\title{
Sobre asfalto e flores: livro, leitura, literatura e biblioteca no Brasil pós-golpe de 2016
}

\author{
André Magri Ribeiro de Melo ${ }^{1}$
}

A Lula e Dilma, ex-presidentes que acreditaram num Brasil menos desigual,

ajudaram a construí-lo e ampliaram a democratização do acesso ao livro, à leitura, à literatura e à biblioteca para os mais pobres.

A Fernando Haddad e Manuela D'Ávila, excandidatos à presidência da república nas eleições de 2018 que fizeram da educação, dos livros e do conhecimento símbolos do diálogo, da resistência e da luta antifascista.

Preciso ainda saber se na verdade existe a indiferença: se não é - e só isto - um disfarce da cumplicidade. Busco as respostas dentro da noite e é como se estivesse nos intestinos de um cão. A sufocação e a sujeira, por mais

que procure defender-me, fazem parte de mim - de nós. Pode o espírito a tudo sobrepor-se? Posso manter-me limpo, não infeccionado, dentro das tripas do cão? Ouço:

"A indiferença reflete um acordo, tácito e dúbio, com os excrementos". Não, não serei indiferente.

Osman Lins, em Avalovara.

Resumo: Em tempos de golpe contra a democracia brasileira e recrudescimento das forças autocráticas e fascistas, é incontornável o debate sobre o lugar do livro, da leitura, da literatura e da biblioteca na cena pública atual. Neste ensaio, teço breves considerações sobre alguns impactos das atuais políticas do governo federal - e da ascensão político-discursiva da extremadireita brasileira - nos processos de democratização do direito à leitura e à cultura escrita. Por fim, aponto conquistas e estratégias de resistência de grupos e movimentos sociais ligados à formação de leitores, à cadeia produtiva do livro e à ampliação do acesso à literatura.

Palavras-chave: Livro e Leitura. Literatura. Biblioteca. Golpe de 2016.

\footnotetext{
${ }^{1}$ Doutorando em Estudos Literários: Literatura Brasileira pelo Pós-Lit (UFMG).
} 
Abstract: In times of a coup against brazilian democracy and the recrudescence of autocratic and fascist forces, the debate over the place of the book, of reading, of literature and of the library in the present public scene is unavoidable. In this essay, I briefly consider some of the impacts of the current federal government policies - and the political-discursive rise of the Brazilian right-wing - in the processes of democratization of the right to read and written culture. Finally, I point out achievements and resistance strategies of groups and social movements linked to the formation of readers, the productive chain of books and the expansion of access to literature.

Keywords: Book and Reading. Literature. Library. Coup of 2016.

Resumen: En tiempos de golpe contra la democracia brasileña y recrudecimiento de las fuerzas autocráticas y fascistas, es incontornable el debate sobre el lugar del libro, de la lectura, de la literatura y de la biblioteca en la escena pública actual. En este ensayo, hago breves consideraciones sobre algunos impactos de las actuales políticas del gobierno federal - y de la ascensión político-discursiva de la extrema derecha brasileña - en los procesos de democratización del derecho a la lectura ya la cultura escrita. Por último, apunto conquistas y estrategias de resistencia de grupos y movimientos sociales ligados a la formación de lectores, a la cadena productiva del libro y a la ampliación del acceso a la literatura.

Palabras clave: Libro y Lectura. La literatura. Biblioteca. Golpe de 2016.

Dentro das tripas do cão. A metáfora perturbadora que Osman Lins dispõe aos leitores em seu romance Avalovara (1973) sugere um ambiente sujo e sufocado onde a possibilidade de contaminar-se é iminente. Abel, o narrador, questiona a indiferença como alternativa. Desconfia da sua condição asséptica e parece pensá-la mais como um disfarce para a cumplicidade e firmação de acordos ambíguos com as forças que nos empurram para os intestinos apodrecidos do cão do que como uma postura apenas desinteressada. Indiferença. Acordo dúbio com os excrementos. Sua decisão frente à falsa contenda é abertamente opositiva, não lhe cabendo nada além do posicionamento ativo em tempos de partido, tempos de homens e mulheres partidos, à lembrança dos versos de Drummond.

À época da publicação desse texto, nosso país vivia um período sombrio da sua história política, marcado pela ascensão autoritária das forças militares ao poder, que se arrastou por mais de duas décadas obscurantistas. Retomo o discurso adotado pelo narrador do romance, carregado de suspeição quanto à indiferença do escritor diante de um cenário insensível e arbitrário, para lançar algumas provocações sobre questões do livro, da leitura, da literatura e da biblioteca no âmbito sociopolítico do Brasil pós-golpe de 2016. Com isso, marco minha intenção de discutir - sem pretensões totalizantes ou exaustivas - aspectos da democratização nacional da leitura e da cultura escrita em meio 
aos impasses e contradições operados na esfera cultural pública após a deposição da presidenta Dilma Rousseff.

Discutir a formação de leitores, especialmente de literatura, no Brasil é parte de um projeto político que tem conjugado diferentes pessoas, movimentos, organizações e instituições em torno da luta pelo direito à leitura e à escrita no país. Um projeto de educação e formação crítica para a liberdade, onde ler, escrever, ouvir e enunciar são ações fundamentais. As décadas de 1980 e 1990 foram transfiguradas pela virada linguística e suas ressonâncias nos modos de conceber e relacionar linguagem e realidade. Estas mudanças paradigmáticas revitalizaram a produção acadêmica brasileira e deram fôlego a um projeto de ensino/pesquisa de língua articulado à valorização do sujeito, dos seus saberes e experiências sociais dentro da escola e da universidade. Uma necessidade político-pedagógica ganhava contornos decisivos nos processos de produção de conhecimento: refletir sobre os papéis que a leitura e a literatura, com ênfase nos modos de participação dos indivíduos e comunidades nessas práticas, deveriam cumprir na educação linguística e artística dos brasileiros, nos cotidianos do país e nas formas de existência dos seus diferentes povos.

Concomitante a esse período de ruptura e fertilidade intelectual foi o processo de redemocratização do país, resultante de intensa crise socioeconômica e das pressões e resistências da população à alta inflação, ao sucateamento da educação e da saúde públicas e ao cerceamento das liberdades individuais e dos movimentos sociais, agudamente reprimidos pelos militares. Um texto capital à discussão sobre a democratização da leitura e da cultura escrita em contexto nacional remonta ao pós1985. Trata-se do ensaio "O direito à literatura”, do crítico literário, sociólogo e professor universitário Antonio Candido (1918-2017), publicado em 1988, ano de nossa última constituinte e quando se discutiam extensivamente direitos fundamentais ao povo.

Um dos intelectuais brasileiros mais empenhados na tarefa de pensar dialeticamente nosso país e sua literatura, Antonio Candido cumpriu no século XX trabalho semelhante ao dos modernistas de 1922, aos quais o professor se referiu como geração heroica e cuja principal contribuição foi alçar escritores e artistas ao espaço da liberdade de expressão e criação. A responsabilidade social foi um traço de destaque no frenesi da fase fundante de um dos principais movimentos estético-políticos brasileiros e tal peculiaridade também é observável na obra crítico-sociológica candidiana, 
notadamente influenciada pela formação marxista do autor. Assim, tanto entre intelectuais do primeiro segmento modernista (a exemplo de Mário de Andrade, Oswald de Andrade, Menotti Del Picchia, Tarsila do Amaral e Anita Malfatti), como a partir do próprio Antonio Candido, não era possível pensar a literatura detendo-se exclusivamente à sua dimensão estética, sem interrogar suas conotações político-sociais na formação da imaginação e do imaginário brasileiros.

Não é por acaso que ao discutir direitos humanos e literatura, Antonio Candido defende que aquilo que consideramos indispensável para nós também o seja para os outros. Essas necessidades devem ser reconhecidas tanto no plano fisiológico, a exemplo das condições de moradia e nutrição favoráveis à vida, como também em relação a outras demandas, como a pintura, a música, o teatro, a dança e a literatura, assertiva que leva à complexificação do debate por tensionar e até mesmo borrar as fronteiras que estabelecem o que é ou não necessário à vida humana. Quanto a isso, Candido comenta:

[...] a tendência mais funda é achar que os nossos direitos são mais urgentes que os do próximo. Nesse ponto as pessoas são frequentemente vítimas de uma curiosa obnubilação. Elas afirmam que o próximo tem direito, sem dúvida, a certos bens fundamentais, como casa, comida, instrução, saúde, coisas que ninguém bem formado admite hoje em dia que sejam privilégio de minorias, como são no Brasil. Mas será que pensam que o seu semelhante pobre teria direito a ler Dostoiévski ou ouvir os quartetos de Beethoven? Apesar das boas intenções no outro setor, talvez isto não lhes passe pela cabeça. E não por mal, mas somente porque quando arrolam os seus direitos não estendem todos eles ao semelhante. Ora, o esforço para incluir o semelhante no mesmo elenco de bens que reivindicamos está na base da reflexão sobre os direitos humanos (CANDIDO, 2011, p. 172).

As preocupações de Candido e dos modernistas e tantos outros quanto ao acesso da população à cultura escrita, ao livro e à leitura são históricas e dão testemunho dos diferentes momentos de defesa pública do direito à educação e, no limite, do direito à vida. Por outro lado, tais convocatórias ao livre pensamento e à luta pela democratização de bens culturais, como a literatura e a escrita, não têm se cumprido com o grau de engajamento epistêmico-político necessário à transformação radical de uma realidade que ainda nos acompanha como um dos principais efeitos das desigualdades e injustiças sociais seculares de nosso país: o analfabetismo.

De acordo com informações do módulo Educação da Pesquisa Nacional por Amostra de Domicílios (PNAD), divulgada pelo IBGE em 18 de maio de 2018, sobre a alfabetização no país, 11,5 milhões de brasileiros ainda não sabem ler e escrever. A 
situação é intensificada quando olhamos para o Nordeste, que mesmo tendo crescido economicamente nos governos petistas, é a região com maior número de pessoas privadas do direito à educação formal. A pesquisa ainda revela que a incidência do analfabetismo chega a ser quase três vezes maior entre a população sexagenária e mais que o dobro entre pretos e pardos, desvelando os efeitos da ausência de políticas públicas eficientes e continuadas para garantir o acesso, a permanência e o êxito de adultos, idosos e negros na educação básica.

As disparidades socioculturais e econômicas que compõem nossos cotidianos desiguais produzem ativamente, há séculos, invisibilidade e silenciamento da população mais pobre do país - que também é feminina e negra, em sua maior parte. Antonio Candido também se ocupa dessa situação ao discutir a noção de literatura como direito basilar à humanização do indivíduo, adotando uma posição política importante ao defender que qualquer um possa ler o que ele chama de literatura erudita.

Particularmente, assumo a crítica em relação à oposição erudito/popular no âmbito cultural em função das inflexões e hierarquias infundadas que esse binarismo pode gerar ao negar a complexidade de alguns textos e manifestações literárias em detrimento de outros e, com isso, reduzir as relações antropológicas entre diferentes autores, leitores e obras a um simulacro de ambivalência desproporcional. De todo modo, cito a avaliação do professor por acreditar que ela presta relevante contribuição ao desnudar nosso olhar para o direito do cidadão comum a produtos culturais pertencentes ou não à sua vida cotidiana. A negação dessa condição às pessoas comuns não é inofensiva ou parte do acaso, mas é uma armadilha fabricada pelas elites socioculturais para deslegitimar seus saberes, experiências - relegados a generalidades folclóricas - e, consequentemente, elas como corpos esvaziados de valor, humanidade e passíveis de exploração.

A organização da sociedade pode restringir ou ampliar a fruição deste bem humanizador [a literatura]. $\mathrm{O}$ que há de grave numa sociedade como a brasileira é que ela mantém com a maior dureza a estratificação das possibilidades, tratando como se fossem compressíveis muitos bens materiais e espirituais que são incompressíveis. Em nossa sociedade há fruição segundo as classes na medida em que um homem do povo está praticamente privado da possibilidade de conhecer e aproveitar a leitura de Machado de Assis ou Mário de Andrade. Para ele, ficam a literatura de massa, o folclore, a sabedoria espontânea, a canção popular, o provérbio. Estas modalidades são importantes e nobres, mas é grave considerá-las como suficientes para a grande maioria que, 
devido à pobreza e à ignorância, é impedida de chegar às obras eruditas. [...] Para que a literatura chamada erudita deixe de ser privilégio de pequenos grupos, é preciso que a organização da sociedade seja feita de maneira a garantir uma distribuição equitativa dos bens. Em princípio, só numa sociedade igualitária os produtos literários poderão circular sem barreiras, e neste domínio a situação é particularmente dramática em países como o Brasil, onde a maioria da população é analfabeta, ou quase, e vive em condições que não permitem a margem de lazer indispensável à leitura. Por isso, numa sociedade estratificada deste tipo a fruição da literatura se estratifica de maneira abrupta e alienante (CANDIDO, 2011, p. 186-187).

O comentário de Antonio Candido, no que toca ao indissociável diálogo entre literatura e política, ratifica a necessidade de ampliar o debate sobre a formação de leitores no Brasil em consonância com outras lutas e demandas, como condições de trabalho adequadas e salários justos, moradia de qualidade e espaço temporal e físico para lazer. Não é raro nos depararmos com discursos em defesa da promoção da leitura, sobretudo literária, sendo encampados em meio a promessas de uma experiência fácil, sempre prazerosa, simples e à disposição do leitor. Há aí um sério equívoco, pois esse tipo de retórica apaga a dimensão de trabalho da leitura, exercício que requer competências linguísticas, cognitivas, históricas, sociais e culturais.

Ler demanda a mobilização de conhecimentos múltiplos para elaborar compreensões, significações e sentidos a partir das páginas de papel ou digitais. Ler pede tempo e compromisso ao leitor. Numa sociedade avassalada pelas mordazes relações capitalistas de produção e consumo exacerbados, como trabalhadoras e trabalhadores que acordam pela madrugada para trabalhar e só retornam às suas casas à noite, já exaustos das rotinas de trabalho (precarizado, não raro), podem cultivar uma experiência literária para além do que seus cotidianos dispõem (como as telenovelas)?

É escandaloso o quadro de retrocessos que atingiu o país durante e após o golpe parlamentar de 2016, que culminou com a o impeachment da presidenta legitimamente eleita, Dilma Rousseff, a partir de um conluio sustentado por conglomerados empresariais, setores do poder judiciário e a chamada grande mídia (audiovisual e impressa). Nos campos da educação, da ciência e da cultura, contabilizamos perdas em diferentes frentes, capitaneadas pelo maior dos ataques ao bem-estar social e à justiça coletiva: a aprovação da Emenda Constitucional 95/2016, que, dentre outras providências, instituiu um Novo Regime Fiscal para o Brasil que congelou por 20 anos os investimentos públicos em políticas sociais.

Some-se a isso a antipolítica de desvalorização dos profissionais do magistério e 
um conjunto de decisões problemáticas em relação às questões curriculares, como a Base Nacional Comum Curricular aprovada pelo Conselho Nacional de Educação em $2017^{2}$, que impõe, sobre a roupagem de uma pretensa democracia dos conhecimentos, o tratamento enviesado e lacunar de saberes, modos de aprender e formas de experienciar o ensino que fragilizam a diferença como princípio unificador e acabam revalidando a marginalização de culturas e experiências subtraídas dos espaços escolares e da própria vida nacional.

Negros, mulheres, homossexuais, transexuais, povos do campo e das periferias, comunidades tradicionais, povos da água, povos indígenas, deficientes físicos, entre outros, figuram entre os excluídos da sociedade e da escola: os não herdeiros ${ }^{3}$, conforme Bourdieu (1998); que são postos à margem do mundo e para quem olhamos sem enxergar à medida que suas próprias existências como sujeitos epistêmicos são deslegitimadas e atacadas constantemente por não pertencerem às castas dominantes socioeconomicamente.

$\mathrm{Na}$ contramão de pesquisas do Currículo ${ }^{4}$ das últimas décadas e de diferentes

\footnotetext{
${ }^{2} \mathrm{Na}$ contramão do MEC e de institutos e fundações empresariais, o discurso celebratório da Base Nacional Comum Curricular encontra forte resistência e oposição entre as entidades científicas vinculadas à educação, como é o caso da ANPEd (Associação Nacional de Pós-Graduação e Pesquisa em Educação) e da ABdC (Associação Brasileira de Currículo), que publicaram manifestos assinados pelos pesquisadores (as) que compõem seus quadros apontando diversas lacunas teóricas e políticas nos textos apresentados pelo MEC e nas próprias diretrizes de organização do processo de discussão e debate públicos envolvendo a Base e seus objetivos de aprendizagem, da educação infantil ao ensino médio. Em 29/11/2015, a ANPEd publicou, por meio do Grupo de Trabalho 12: Currículo, e com apoio da $\mathrm{ABdC}$, manifesto contrário ao documento orientador de políticas públicas para a Educação Básica apresentado pela SEB/MEC para a consulta pública como Base Nacional Comum Curricular. O documento pode ser acessado neste link: http://www.anped.org.br/sites/default/files/resources/Of cio 012015 CNE BNCC.pdf. Em 2017, no contexto das audiências públicas para a avaliação da $3^{a}$ versão do documento, a ANPEd e a ABdC manifestarem-se novamente em relação à condução do processo de construção da Base. Neste link: http://www.anped.org.br/news/associacao-brasileira-de-curriculo-abdc-encaminha-documento-ao-cneno-contexto-das-audiencias é possível acessar documento encaminhado pela $\mathrm{ABdC}$ ao Conselho Nacional de Educação denunciando a ausência de uma "efetiva discussão democrática do que poderia ser um base nacional comum curricular inclusiva, respeitosa e plural", o que é ratificado por nota lançada pela ANPEd, que pode ser acessada aqui: http://www.anped.org.br/news/nota-daanped-sobre-entrega-da-terceira-versao-da-base-nacional-comum-curricular-bncc-ao, insistindo que o processo de elaboração da Base "subalterniza o diálogo com as comunidades escolares".

${ }^{3}$ Compreendo o comportamento de indivíduos herdeiros para além do recebimento de uma herança cultural, econômica, simbólica ou social, mas sobretudo considerando também o trabalho que eles realizam para se apropriarem do capital mobilizado por essa herança "destinada" a eles. O não herdeiro opera na direção contrária (em parte), pois não recebe dos seus antecessores herança (nos termos bourdieusianos). Acerca do uso do termo herdeiro, ver os trabalhos de Pierre Bourdieu \& Jean-Claude Passeron (1967); os escritos de Pierre Bourdieu reunidos em livro por Maria Alice Nogueira e Afrânio Catani (2015); e os de Bernard Lahire (2004, 2006).

${ }^{4}$ Algumas dessas pesquisas podem ser consultadas nos trabalhos de Miguel Arroyo (2017; 2012a; 2012b) e Marlucy Alves Paraíso (2004; 2010; 2015), ambos professores da Faculdade de Educação da Universidade Federal de Minas Gerais (UFMG).
} 
áreas de estudo ligadas à educação que apontam o baixíssimo impacto de documentos elaborados à revelia de debates sérios e coletivos na vida escolar e no trabalho docente, o regime de ilegitimidade no qual vivemos enseja e apoia iniciativas que minam a educação das camadas populares e criam condições para que esta seja cada vez mais vinculada à regência tecnocrata do conhecimento, castrando suas dimensões políticosociais e subjetivas e desfavorecendo possibilidades de transformação individual e coletiva dos sujeitos.

A Reforma do Ensino Médio também corrobora esse cenário de desmonte da educação pública, pois fere a Lei de Diretrizes e Bases da Educação Nacional no que toca à garantia do Ensino Médio como etapa da educação básica vinculada à formação integral de todo cidadão e concentra suas forças em duas propostas de educação, uma para o operário (homo sacer), outra para o "que pensa" (homo sapiens), conforme analogia do especialista em legislação educacional Carlos Jamil Cury (PUCMG/UFMG). O que a Lei no 13.415/2017, resultante da Medida Provisória no 746/2016, opera na prática é a cisão entre formação intelectual e formação técnica, esvaziando a dimensão críticoartística do Ensino Médio e reduzindo o papel formativo e a experiência curricular dos jovens ao que julga como "fundamental": língua portuguesa, matemática e língua inglesa, únicos componentes curriculares obrigatórios ao longo dos 3 anos.

$\mathrm{O}$ atual estado de aniquilação dos direitos sociais se revela ainda mais tortuoso quando trazemos à tona a educação brasileira no campo, que tem sido historicamente pensada a partir da expropriação de pessoas e pedagogias desse espaço. A chefe do setor de educação do Movimento dos Trabalhadores Rurais Sem Terra (MST), Cristina Vargas, divulgou, em 2016, dados sobre as escolas do campo fechadas na última década. Foram 32.512 escolas, das quais mais de 4 mil somente em 2014, que tiveram suas portas trancadas.

O cenário não é favorável às populações rurais, sejam trabalhadores adultos ou crianças e jovens, tendo em vista a redução do orçamento para o Programa Nacional de Educação na Reforma Agrária (PRONERA), que caiu de 30 milhões de reais, em 2016, para 11 milhões, em 2017, e 3 milhões de reais para 2018. A queda de investimentos na Educação de Jovens e Adultos (EJA), segmento que acolhe milhões de estudantes das zonas rurais do país, também foi drástica, com apenas 1,1 milhão de reais executados até outubro de 2017, de uma destinação orçamentária de 28 milhões para o ano. Além disso, 
com a suspensão, desde 2016, do Programa Brasil Alfabetizado, inaugurado em 2003, e que tinha como objetivo alfabetizar pessoas jovens e adultas fora da idade escolar, os caminhos para apropriar-se da leitura e da escrita como direitos de aprendizagem constitucionais se tornaram mais estreitos e difíceis para o público-alvo dessas políticas.

No campo da educação literária e da formação de leitores, o principal programa de distribuição de livros para as bibliotecas escolares e também o principal canal de acesso a livros de literatura para a amplíssima maioria das crianças e jovens pobres do país, o Programa Nacional Biblioteca da Escola (PNBE), também tem sofrido represálias. Em 2015, sob os efeitos da crise econômica internacional que já haviam sido divulgados em 2013 e foram intensificados por decisões equivocadas na economia nacional e pela crise política fabricada pelos partidos de oposição ao governo federal, o Ministério da Educação (MEC) anunciou que não haveria aquisição de novos livros para 2016. A notícia foi recebida com indignação pelos setores da cadeia produtiva do livro, organizações ligadas à promoção da leitura e à formação de leitores, agentes da educação básica pública e pesquisadores das políticas públicas do livro, da leitura, da literatura e das bibliotecas. Não é desnecessário lembrar que a escola é, desde a democratização do acesso ao ensino fundamental, um lugar de encontro privilegiado entre muitos brasileiros e a literatura (especialmente a escrita) e que a fragilização das ações de Estado em relação à formação de leitores incide direta e significativamente nas possibilidades de educação literária desse público.

A gestão ilegítima do Ministério da Educação só deu o primeiro sinal de informação sobre o programa, paralisado poucos meses antes do início do golpe de 2016, em maio de 2017, quando anunciou o estudo da sua retomada, embora com modificações. Ora, são estas pretensas mudanças que, ao invés de lidar com os equívocos do antigo PNBE, acabam aprofundando-os como reflexos dos abismos políticos e pedagógicos com os quais nos confrontamos atualmente.

Sem discussão pública densa e ignorando a produção acadêmica e a experiência pedagógica das comunidades escolares na formação de leitores e no ensino de literatura, o MEC não questiona aspectos fundamentais à compreensão dos porquês da subutilização dos acervos do PNBE em algumas escolas - um dos problemas alegados pela nova equipe do ministério. A ausência de políticas de formação em ensino/mediação da leitura para os educadores e bibliotecários, a falta de bibliotecas 
escolares $^{5}$ ou má conservação/manutenção das que existem e a desarticulação entre políticas federais e locais para promoção da leitura são alguns dos pontos que ficam em suspenso no discurso governamental; além do desprestígio social da docência, dos salários desestimulantes e das péssimas condições estruturais das escolas públicas protagonistas de longa data desta seara de problemas que não podem ser dissociados do debate público sobre a leitura, a literatura e a formação de leitores.

Esse estado de incertezas em relação ao PNBE se consolidou com a criação do PNLD Literário, um segmento do Programa Nacional do Livro e do Material Didático que se ocupará do envio de obras literárias aos estudantes a partir da chancela dos conteúdos da Base Nacional Comum Curricular e de temas pré-fixados no Edital 02/2018 - CGPLI/SEB/MEC. O edital de convocação às editoras não prevê o envio de livros às bibliotecas escolares, salvo no caso do item 2.1.2 dos seus objetivos, onde se lê: "apoiar a formação dos acervos das escolas públicas, ampliando as oportunidades de uso individual dos estudantes de literatura de qualidade durante o ano letivo" (destaque meu).

No entanto, de acordo com informações divulgadas no site do PNLD Literário, as escolas que atendessem estudantes das categorias $5\left(4^{\underline{0}}\right.$ e $5^{\underline{o}}$ anos do Ensino Fundamental) e 6 (Ensino Médio) poderiam escolher até 50 obras para compor seus acervos bibliotecários; alunos dessas mesmas categorias devem receber, cada um, dois livros para uso pessoal. Com relação às categorias 1 (Creche I - o a 1 ano e 6 meses), 2 (Creche II - 1 ano e 7 meses a 3 anos e 11 meses) e 3 (Pré-escola - 4 a 5 anos e 11 meses), serão enviados conjuntos de 20 obras para as salas de aula, assim como no caso da categoria 4 (1a ao $3^{\circ}$ ano do Ensino Fundamental), que deverá receber 35 livros. Observase, assim, que no caso das categorias 1 a 4, não serão enviados livros literários às bibliotecas.

As orientações para destinação dos livros de literatura que chegarão às escolas parecem pretender, a priori, uma diversificação dos espaços que essas obras poderão

\footnotetext{
${ }^{5}$ Os prefeitos e governadores desrespeitam a Lei $12.244 / 10$ que exige que até 2020 todas as instituições públicas e particulares de ensino tenham bibliotecas. Atualmente, precisaríamos construir mais de 65 bibliotecas escolares por dia para que essa Lei fosse cumprida e as crianças tivessem garantido o acesso ao conhecimento pela leitura e à literatura. É preciso destacar que o desrespeito é ainda maior quando alguns gestores públicos fecham salas de leitura, bibliotecas, salas de informática e brinquedotecas com a desculpa de precisar transformá-las em salas de aulas, o que ocorreu na rede estadual de ensino do RN entre os anos de 2011 e 2014.
} 
ocupar: sala de aula, casa do aluno e biblioteca escolar. Contudo, as pretensões são problemáticas se considerarmos alguns aspectos da sua operacionalização, a exemplo da distância que se construirá entre crianças da educação infantil e do ciclo de alfabetização e a biblioteca escolar, tendo em vista que o governo não pretende ampliar os acervos desses espaços para as crianças de o a 8 anos de idade.

O acesso desse público à experiência literária construída e mediada na biblioteca é fundamental à sua formação, não podendo se restringir ao contato com alguns livros específicos para sua faixa etária (conforme determinação do edital) que estão em sua sala. Pensada como território interdisciplinar, cabe à biblioteca escolar conjugar diversidade de temas, pluralidade de textualidades e variedade de materiais e objetos de leitura para diferentes tipos de leitores em formação. Ela não pode ser reduzida a um local onde a professora levará as crianças, de vez em quando, com os livros da própria sala de aula para desenvolver alguma tarefa. A biblioteca na escola deve ser, por excelência, o lugar de encontro entre crianças, livros, leituras e literaturas, ocupando centralidade nos processos de educação, ensino e aprendizagem e negando qualquer utilitarismo acessório que esvazie sua dimensão política, artística e crítica.

Manter os livros de literatura infantil apenas na sala de aula também pode implicar no desconhecimento e na desvalorização desse tipo de obra de arte na biblioteca e na escola, se observarmos que eles ocuparão um lugar restrito na dinâmica do cotidiano escolar. Ressalvo que não vejo impedimento à presença de livros literários na sala de aula, mas que essa ação pode limitar a formação estética e sensível das crianças quando não conectada a outras ambiências, atividades e pessoas da escola. Manter livros literários na sala e não levá-los à biblioteca é corroborar o discurso valorativo e preconceituoso de parte da crítica literária e da academia brasileira que marginaliza o estatuto artístico da literatura para crianças, reduzindo-a a um conjunto de textos pedagogizantes referendados pela indústria cultural - equívoco retumbante já desmontado por uma tradição já consolidada de estudos e produção das literaturas infantil e juvenil no Brasil, que inclui escritores, ilustradores, editores, pesquisadores e outros profissionais em intensa atividade desde o século XX.

O envio de livros, prioritariamente, a alunos e salas de aula, as indeterminações que pairam sobre o PNBE e o caráter deficitário que os acervos escolares assumem no PNLD Literário podem incorrer, a médio e longo prazo, na precarização das bibliotecas, 
que diante das incertezas sobre a total renovação dos seus acervos e a manutenção dos seus espaços tendem a enfraquecer sua possibilidade de atuação dentro da escola e da comunidade onde estão, sobretudo em relação às crianças da primeira infância e/ou em processo de alfabetização. É prudente reiterar também que paralela à importância do uso individual das obras literárias, a experiência de leitura em espaços e práticas pedagógicas coletivos também é fundamental à formação de leitores literários na educação básica, em qualquer etapa ou modalidade, o que ratifica a relevância das bibliotecas escolares e a necessidade de mantê-las abertas, com condições de uso adequadas e acervos renovados.

$\mathrm{Na}$ história das políticas públicas do livro e da leitura no Brasil, figuram experiências controversas envolvendo a distribuição de livros para uso pessoal de alunos, como é o caso do programa Literatura em Minha Casa. Essa ação incidiu negativamente sobre a produção artístico-literária e editorial de livros, que perderam qualidade material e simbólica em detrimento da quantidade de exemplares enviados aos estudantes. Muitas das obras não traziam os textos originais integralmente, eram produzidas dentro de um formato único, apelando para textualidades e materialidades simplórias e pouco inovadoras por causa do barateamento, além de serem impressas em preto e branco. O Edital do PNLD Literário, a princípio, não parece buscar um modelo único de livro literário nos moldes do programa mencionado, ainda que fixe formatos específicos para as obras destinadas aos anos iniciais do Ensino Fundamental e ao Ensino Médio e traga uma lista extensa de especificidades técnicas obrigatórias quanto às capas, números de páginas, tipos de papel, entre outros, o que tem sido criticado por setores da cadeia produtiva do livro.

A Liga Brasileira de Editores (LIBRE), que representa mais de 100 editoras independentes, enviou carta ao FNDE quando o edital foi lançado em abril de 2018. No documento, a agremiação criticou as regras do edital alegando que elas dificultavam e restringiam a participação de editoras independentes, pois reduziam "a oferta de diversidade para os alunos da rede pública", o que encerraria "um desrespeito com estes mesmos alunos como leitores e consumidores de livros". Alegando "ataque à igualdade na cadeia do livro", a carta ainda questiona a padronização dos formatos de livros que serão vendidos ao governo como um mecanismo de favorecimento às grandes editoras: 
Não apenas os grandes grupos econômicos do setor são favorecidos, contrariando o espírito da Constituição de 1988, que prevê o incentivo à ampla concorrência e às empresas de menor porte, os editais impõem regras que resultam no oferecimento aos estudantes de livros que mais se assemelham a apostilas, empobrecidos em seus aspectos físicos, o que contribui para afastar os estudantes de um dos elementos centrais do mundo da leitura: a diversidade de formas que o livro pode apresentar (LIBRE, 2018).

A crítica do grupo de editoras independentes revela o descompasso entre as políticas públicas do livro, da leitura, da literatura e da biblioteca após o golpe de 2016, o que se reflete com mais ênfase na descontinuidade dos programas que já existiam e no diálogo restrito com editores, livreiros, escritores, designers, mediadores, professores, pesquisadores, bibliotecários, movimentos sociais, sociedade civil e outros grupos intimamente ligados ao livro e à leitura no país. O rompimento democrático a que fomos submetidos implicou na ruptura de pressupostos aparentemente consolidados no discurso governamental, como o valor da diversidade cultural na formação literária. Quanto a essa questão, o documento aponta em sua parte final:

\footnotetext{
Ignorando os avanços do Estado brasileiro no reconhecimento da importância da diversidade cultural e editorial brasileira, tais normas do PNLD estimulam a concentração e a homogeneidade cultural. É como se o governo trocasse uma floresta nativa por uma floresta de eucaliptos, em que a biodiversidade é sufocada pela monocultura [...] é preciso entender que os editais em questão representam um atraso enorme no que diz respeito à diversidade editorial. $\mathrm{O}$ governo praticamente reconhece que, em vez de bons livros para os alunos da escola pública, ofertará exemplares estandardizados e, consequentemente, com menos viço. O setor público, assim, explicita um preconceito contra os mais pobres, que ficam privados da qualidade editorial disponível para os leitores que podem pagar por livros nas livrarias (LIBRE, 2018).
}

Além dos problemas no campo dos critérios que regem a materialidade dos livros literários no PNLD, estão as objeções quanto ao condicionamento dos acervos aos conteúdos previstos nos objetivos de aprendizagem da Base Nacional Comum Curricular e aos temas pré-fixados no próprio edital. A delimitação pode ter consequências improdutivas nos processos de formação crítica dos leitores e seus repertórios, considerando que as fronteiras da BNCC e do edital podem restringir o espaço para a descoberta, a possibilidade e a invenção nas dinâmicas individuais e coletivas de leitura nos espaços escolares.

Divulgada no segundo semestre de 2018, a lista de obras selecionadas para o Guia 
do PNLD literário já passou pelas escolas, que selecionaram os títulos que chegarão aos seus alunos. Ainda é cedo para avaliar até que ponto os temas do edital e da BNCC influenciaram as escolhas das comunidades escolares, mas o esperado é que nenhum documento - sejam diretrizes/orientações curriculares ou editais - atue como censor à liberdade, à criatividade e à ampliação de horizontes que os escritores e demais produtores de literatura devem ter como pressuposto nas suas obras. A suspeição quanto à correspondência entre acervos literários e conteúdos pré-estabelecidos antecipa o receio de que crianças e jovens sejam autorizados a acessar apenas obras com temas definidos pelo governo, ceifando o pluralismo de ideias e a liberdade de concepções pedagógicas, que são prerrogativas estabelecidas no Título II, Art. $3^{\underline{0}}$, Inciso III, da LDBEN $^{6}$.

Lançado pelo Ministério da Educação em abril de 2018, e consolidado em o4 de junho de 2018 após retificações demandadas por associações e outras organizações do livro e da leitura, o primeiro edital do PNLD Literário veio à lume com incoerências e equívocos. A recepção crítica de parte da cadeia produtiva do livro e outros agentes envolvidos no mercado da leitura e na formação de leitores aponta para o caráter arbitrário do documento, que estaria ferindo princípios basilares da democratização da leitura e da literatura nas escolas ao fixar parâmetros rígidos para a seleção das obras. Alheio à parte das diretrizes do Plano Nacional do Livro e da Leitura (PNLL), que remontam a 2006, ao conhecimento e às experiências produzidas nas últimas décadas nas áreas de educação, estudos literários, artes, design, edição e políticas públicas, o documento divulgado pelo MEC não se afina, em diversos aspectos, com referenciais científicos e artísticos contemporâneos que deveriam guiar o maior programa de compra e distribuição de livros do mundo.

A diretriz ministerial ignora algumas condições específicas de criação, produção, circulação, consumo e recepção de obras literárias e fragiliza a complexidade dos processos de escolarização da leitura e letramento literário. Um desses exemplos é a fixação de conteúdos curriculares como campo dentro e a partir do qual escritores e ilustradores deverão ater-se para produzir. Além de estabelecer conteúdos para a literatura, o edital regula formas, práticas e modos de ler literariamente com o argumento das divisões etárias. Com isso, incorre na determinação de modelos e

\footnotetext{
${ }^{6}$ Lei no 9394/1996 - Lei de Diretrizes e Bases da Educação Nacional.
} 
formatos específicos para as obras e instrumentaliza inadequadamente o ensino da literatura por meio da solicitação subentendida do envio de manuais didáticos aos professores. Mesmo que apareça facultativa no edital, essa possibilidade teve a adesão da maioria dos livros selecionados pelo MEC e posteriormente pelas escolas.

As funções da literatura previstas no Plano Nacional do Livro e da Leitura (2006), inspiradas nas reflexões de Antonio Candido, sofrem, no âmbito do edital e do programa, apagamentos e distorções que podem comprometer a formação literária nos espaços escolares, sobretudo pela forma como a qualidade dos textos é pensada. Tratada hermeticamente, a literatura pode ver comprometida a sua capacidade de atender à "nossa imensa necessidade de ficção e fantasia" e de exercer "sua natureza essencialmente formativa, que afeta o consciente e o inconsciente dos leitores de maneira bastante complexa e dialética, como a própria vida, em oposição ao caráter pedagógico e doutrinador de tantos outros textos”. Enfim, nos moldes como o atual MEC concebe política e artisticamente a literatura, há um evidente esvaziamento do "seu potencial de oferecer ao leitor um conhecimento profundo do mundo, tal como faz, por outro caminho, a ciência" (BRASIL, PNLL, 2006, p. 22).

A tentativa de higienização da diferença, do conflito, da divergência, da pluralidade e da diversidade de lugares, posições, opiniões, pessoas e culturas na escola, cabe recordar, é uma das bases do dogmatismo ultraconservador vigente na autoritária7 sociedade brasileira em que vivemos, especialmente após o golpe de 2016. Os projetos de lei ligados ao programa Escola sem Partido $^{8}$, por exemplo, têm como cerne o

\footnotetext{
${ }^{7}$ Quando me refiro às atuais reverberações do autoritarismo na sociedade brasileira quero ratificar o estado político, moral e ético que temos vivido ao longo da nossa história e que, nos últimos anos, tem ganhado dimensões e contornos nocivamente amplificados que implicam em perigo para o que estabelece a legislação central da educação brasileira em relação à pluralidade de opiniões e à liberdade de concepções pedagógicas - aspectos que julgo basilares à formação de leitores em âmbito escolar ou não -, a Lei de Diretrizes e Bases da Educação Nacional. Acerca do conceito de autoritarismo, recorro à definição da filósofa Marcia Tiburi, que caracteriza esta palavra como desígnio de um "modo antidemocrático de exercer o poder", destacando que "a centralidade é o atributo ou a característica de um governo, de uma pessoa ou até mesmo de uma cultura, que fornece o núcleo gerador da ação no exercício do poder autoritário". A autora ainda reforça que o diálogo e a participação coletiva "são impensáveis no espectro do autoritarismo que se define pela imposição à força de leis que interessam a quem exerce o poder", o que desemboca no outro, "seja o povo (Estado), seja o próximo (indivíduo), seja a sociedade ou outras formas de cultura", lido como algo/alguém manipulável, "quando não violentado, tanto física quanto simbolicamente" (TIBURI, Marcia. Como conversar com um fascista: reflexões sobre o cotidiano autoritário brasileiro. Rio de Janeiro: Record, 2016, p. 25).

${ }^{8}$ PL 867/2015 e PLS 193/2016, que incluem entre as diretrizes e bases da educação o "Programa Escola sem Partido" e o PL 1411/2015, que tipifica o crime de assédio ideológico e dá outras providências. Para o Coordenador-Geral da Campanha Nacional pelo Direito à Educação, Daniel
} 
apagamento do caráter democrático dos processos educativos a partir do amordaçamento de professores, da proibição de referenciais teóricos e ideias maculados sob a insígnia da "doutrinação ideológica", além da castração de qualquer possibilidade de diálogo da escola e seus sujeitos com questões sociais, políticas e culturais locais e globais, ação que incorreria em subversão da função da escola, como defendem os partidários da iniciativa.

Os contrassensos que observamos desde a tomada de poder pelos golpistas et caterva no campo da leitura e da literatura não se restringem à educação. O próprio Ministério da Cultura (MinC) foi, a princípio, extinguido pelo (pseudo) governo federal. Após intensas críticas e mobilizações sociais, foi mantido, mas os setores diretamente ligados às políticas do livro e da leitura foram alguns dentre os mais atingidos pela nova organização administrativa, levada a cabo por profissionais alheios às questões da pasta e ao movimento histórico de luta em defesa da democratização do acesso à leitura e à cultura escrita, o que resultou em arranjos internos desajustados e fusões injustificáveis, do ponto de vista estratégico, na elaboração e implementação das ações.

A Diretoria do Livro, Leitura, Literatura e Bibliotecas (DLLLB) do MinC sofreu baixas grosseiras. Dezenas de funcionários diretamente ligados a projetos e políticas da pasta e com vasta experiência e atuação no campo cultural e literário foram demitidos, diminuindo a capacidade de ação da diretoria e implodindo a continuidade das políticas públicas que vinham sendo gestadas ou continuadas pela gestão anterior. A saída da DLLLB da Secretaria Executiva do MinC para a Secretaria da Cidadania e Diversidade Cultural (SCDC) representou outra perda para o livro e a leitura que, no entendimento do ex-diretor da pasta, Volnei Canônica, significou o enfraquecimento e a ruptura de articulações construídas nos últimos anos, principalmente porque a SCDC não tem,

Cara, tais projetos têm como base a acusação de que há nas escolas brasileiras um estado de doutrinação moral e ideológica de esquerda e, por isso, caberia vigiar e controlar os professores em sua profissão, o que o educador lê como "imposição de limites à liberdade de cátedra". Segundo o especialista em educação e ciência política, o Escola sem Partido "é inspirado em iniciativas internacionais e declara três objetivos: a 'descontaminação e desmonopolização' política e ideológica das escolas'; o 'respeito à integridade intelectual e moral dos estudantes'; e o 'respeito ao direito dos pais de dar aos seus filhos uma educação moral que esteja de acordo com suas próprias convicções'. $\mathrm{O}$ autor defende que qualquer exercício de julgamento sobre a observância desses três objetivos "criará verdadeiros tribunais ideológicos e morais nas escolas, transformando o espaço escolar em um ambiente arbitrário, acusatório, completamente contraproducente ao aprendizado" (CARA, Daniel. O Programa "Escola sem Partido" quer uma escola sem educação. In: AÇÃO EDUCATIVA ASSESSORIA, PESQUISA E INFORMAÇÃO (Org.). A ideologia do movimento Escola sem Partido: 20 autores desmontam o discurso. São Paulo: Ação Educativa, 2016, p. 44-45). 
dentre seus eixos de ação, a promoção da leitura como centralidade e o deslocamento da DLLLB impacta negativamente a capacidade de intervenção dela nas políticas do MinC.

Em texto publicado em 2016, quando foram iniciadas as reformas do MinC, Canônica alertava que além da saída da DLLLB da Secretaria Executiva para integrar a SCDC, ela ainda foi rebaixada a departamento como resultado da fusão entre Coordenação Geral de Leitura e Coordenação Geral da Literatura e Economia do Livro, que passaram a se chamar de Coordenação Geral de Leitura, Literatura e Economia do Livro. Fundindo essas duas coordenações, a nova gestão demonstrou desconhecimento sobre diferentes aspectos do trabalho ligado ao livro e à leitura que vinha sendo realizado pela diretoria. Alguns exemplos são as ações desenvolvidas pelos comitês do Programa Nacional de Incentivo à Leitura (Proler), a internacionalização da literatura brasileira e a qualificação das feiras e eventos literários. Nas palavras do ex-diretor (2016), "a atual gestão não faz ideia do volume de trabalho, da necessidade de uma continuidade de reflexão para a mudança de paradigmas e das necessidades da área”.

Outro deslocamento equivocado foi o da Biblioteca Demonstrativa Maria da Conceição Moreira Salles, antes sob a coordenação do Sistema Nacional de Bibliotecas Públicas, para a Coordenação Geral de Leitura, Literatura e Economia do Livro. Se as diretrizes para todas as bibliotecas do país são pensadas e oficializadas pela Coordenação do Sistema Nacional de Bibliotecas Públicas, qual o sentido em colocar sob outra jurisdição a coordenação da Biblioteca Demonstrativa? Os erros de articulação e organização acumulam-se uns sobre os outros confirmando a redução da mobilidade ou mesmo sua imobilidade - de operar ações que deságuem na garantia do acesso qualificado da população a diferentes textos, literários ou não.

A formação de leitores e suas diferentes subjetividades é o que está verdadeiramente em jogo nessa cruzada de sucateamento dos serviços e políticas públicas na área do livro e da leitura. Profissionais, equipamentos, projetos e programas correm sérios riscos com cortes humanos e financeiros que têm acometido cada vez mais intensamente a nossa área e suas ações e contribuído para o enfraquecimento do contínuo de democratização do acesso à cultura letrada que vimos caminhar a passos otimistas na última década e meia, mas que agora vemos em derrocada justamente porque os que ora governam - e estão prestes a governar - o país sabem o valor de uma sociedade letrada e leitora e, exatamente por isso, buscam debilitar e destruir todo 
conjunto de esforços que se tem feito para construir um país de leitores: críticos, diferentes, políticos, sensíveis e cientes do seu papel como cidadãos do mundo.

Os movimentos sociais do livro, da leitura, da literatura e da biblioteca, ao lado das universidades, editoras, escritores, ilustradores e outros profissionais, têm protagonizado lutas e resistências às decisões equivocadas do governo federal. A petição pública em repúdio ao edital do PNLD-Literário 2018, organizada pelo Projeto "Leitura e Escrita na Educação Infantil” e pelo Movimento Interfóruns da Educação Infantil MIEIB, é um exemplo das mobilizações e articulações sociais em defesa do direito à leitura e à literatura que têm ganhado corpo e voz no país após o golpe de 2016.

Iniciativa importantíssima, ainda que em outro contexto, é o Manifesto por um Brasil Literário (2009), escrito por Bartolomeu Campos de Queirós no âmbito do Movimento por um Brasil Literário, que conjuga apoios de diferentes instituições e organizações públicas, privadas e não-governamentais na busca por políticas públicas efetivas que fortaleçam o acesso das pessoas à leitura e à literatura e contribuam para a edificação de uma sociedade leitora. Apostando na literatura como um discurso capaz de democratizar “o poder de criar, imaginar, recriar, romper o limite do provável” e possibilitar ao leitor "dobrar-se sobre si mesmo e estabelecer uma prosa entre o real e o idealizado", o texto do manifesto é contundente ao considerar a leitura literária como um direito de todos que precisa ser escrito e dito hoje e amanhã.

A coroação da resistência e das lutas travadas Brasil a dentro e à fora pelo direito ao livro, à leitura, à literatura e às bibliotecas foi a aprovação da Lei no 13.696/2018, sancionada em 12 de julho, e que chancela a Política Nacional de Leitura e Escrita, originada de um projeto de lei de autoria da Senadora Fátima Bezerra (PT-RN), que tramitou cerca de dois anos no Congresso Nacional. Motivo de comemoração em meio a um cenário desanimador e enfraquecido pela desarticulação de ações, desmonte político e diminuição drástica na compra de livros, a aprovação da Lei Castilho - assim batizada, carinhosamente, em homenagem a José Castilho, professor universitário, editor, exdiretor geral da Biblioteca Mário de Andrade (SP) e ex-Secretário Executivo do Plano Nacional do Livro e da Leitura José Castilho; um dos mais incansáveis brasileiros que têm feito da sua vida uma história de defesa inabalável da democracia, da leitura e da emancipação das pessoas - dá novo fôlego aos embates que temos travado em defesa do que é direito de todo cidadão: ler, ficcionalizar, fabular, aprender, questionar, criticar. 
Não se pode esquecer, porém, que a assinatura de Michel Temer sancionando a lei é nada mais que mero procedimento administrativo, pois não existiu da parte dele ou do seu governo qualquer vestígio de contribuição para que a Política Nacional de Leitura e Escrita se tornasse realidade constitucional. Essa conquista tem 12 anos de história, datados simbolicamente desde quando iniciaram as discussões em torno do Plano Nacional do Livro e da Leitura (PNLL) e que se fortaleceram e ganharam corpo e voz por todo o país, reunindo numerosos voluntários, parceiros, companheiros de caminhada que fazem da democracia, da leitura e da literatura motivos pelos quais viver e trabalhar. O governo golpista que tomou de assalto nosso país e tem leiloado os nossos recursos naturais, interrompido fluxos democráticos e atacado direitos materiais e simbólicos não faz parte da história de democratização da cultura escrita brasileira, senão nas páginas relegadas aos excrementos, ao que está nas tripas do cão.

Fernanda Garcia (2018), diretora executiva da Câmara Brasileira do Livro, comenta que existem diferenças entre o Plano Nacional do Livro e da Leitura (PNLL) e a Política Nacional de Leitura e Escrita (PNLE), registrando que mesmo partindo de disposições muito semelhantes e intimamente relacionadas são instrumentos diferentes. Em linhas gerais, o PNLL foi um documento com orientações, diretrizes e metas que objetivavam auxiliar municípios e estados a elaborarem suas políticas públicas locais do livro e da leitura. Já a Política Nacional de Leitura e Escrita conta com um texto mais simples, mas que dada sua condição de lei permite à sociedade cobrar do Poder Executivo a elaboração de um plano com objetivos específicos, coerentes e financiados publicamente que viabilizem a criação e consolidação de políticas de formação de leitores e escritores/produtores de texto.

Portanto, a Lei 13.696/2008 "fixa a regra para que o Ministério da Cultura e o Ministério da Educação elaborem em colaboração o Plano Nacional do Livro e Leitura com os objetivos previstos em seu texto", sendo necessário ouvir o Conselho Nacional de Educação (CNE), o Conselho Nacional de Política Cultural (CNPC) e representantes de secretarias de educação e cultura de estados, distritos e municípios, a sociedade civil e o setor privado. Fernanda Garcia ainda esclarece que nos primeiros seis meses do mandato do presidente eleito esses ministérios devem elaborar o plano que permanecerá válido para a próxima década, período em que deverá ser implantado e executado.

Então, a comemoração mais que justificada de um passo tão importante na luta 
em defesa do direito à leitura e à escrita não pode se encerrar nela mesma, afinal há muito trabalho para continuar sendo feito, inclusive se considerarmos a crise econômica no mercado editorial brasileiro e a cruzada contra os livros e o conhecimento que marca o discurso de grande parte da classe política que estará à frente do país a partir de 2019. A cadeia produtiva do livro, os professores, os pesquisadores, a sociedade, os movimentos sociais, os bibliotecários, os mediadores, agentes de leitura e os leitores precisam atuar individual e coletivamente no acompanhamento do cumprimento da lei, na sua implementação em municípios, estados e distritos e na colaboração com o controle social das políticas e ações, elemento fundamental em sociedades democráticas para avaliar o alcance e os limites dos serviços públicos na vida dos cidadãos e estimular a participação de todos na construção do cotidiano partilhado coletivamente.

Trazer a esse trabalho algumas cenas do Brasil dos últimos anos me parece necessário, já que o ataque à educação, às políticas de distribuição dos livros, à literatura, ao pluralismo de ideias, experiências e concepções pedagógicas são pontos que fundamentam a urgência de nos interrogarmos sobre o espaço da leitura e da experiência literária entre a população brasileira, principalmente a mais pobre, constituída em grande parte por negros e mulheres, o que nos convoca à necessidade de racializar e generificar o debate sobre o direito à leitura no país.

A interrogação sobre a formação de leitores em territórios que são continuamente associados à ignorância, ao iletrismo, ao analfabetismo, ao não literário e ao agrafismo é, além de uma provocação epistêmica, uma provocação política, uma postura de combate ao projeto de indiferença ativamente produzida do capitalismo. Considero que não há ciência sem política, como não há formação de leitor, experiência literária ou práxis pedagógica que passe incólume à política e, reitero, à raça e ao gênero. Num país cuja história é marcada por genocídio, escravidão, golpes, autoritarismo e violência não é possível ignorar que realidade e discurso se amarram e se nutrem simbioticamente. A consciência do papel central da linguagem na vivência, percepção, interpretação e transformação do mundo tem sido, ao longo dessa mesma história sangrenta, uma das principais formas de resistir e garantir direitos, de viver apesar da morte e de produzir memórias mesmo diante da imposição de apagamentos.

Discurso específico numa trama de outros tantos, acredito que a literatura pode abrir diálogos entre subjetividades e materialidades, convocando leitores e obras ao 
desafio duplamente atravessado de viver e sonhar, ambos fiados com as linhas da imaginação e do real. O que já é conhecido e o que está por conhecer são rastros infindáveis que se ligam a redes inapreensíveis de relações e sentidos que afirmam a maleabilidade do pensamento. Reitero as palavras do Manifesto por um Brasil Literário: “a literatura, pela sua configuração, acolhe a todos e concorre para o exercício de um pensamento crítico, ágil e inventivo; compreendendo que a metáfora literária abriga as experiências do leitor e não ignora suas singularidades". A seguir, trago uma fotografia que é mote final dessas breves considerações 9 :

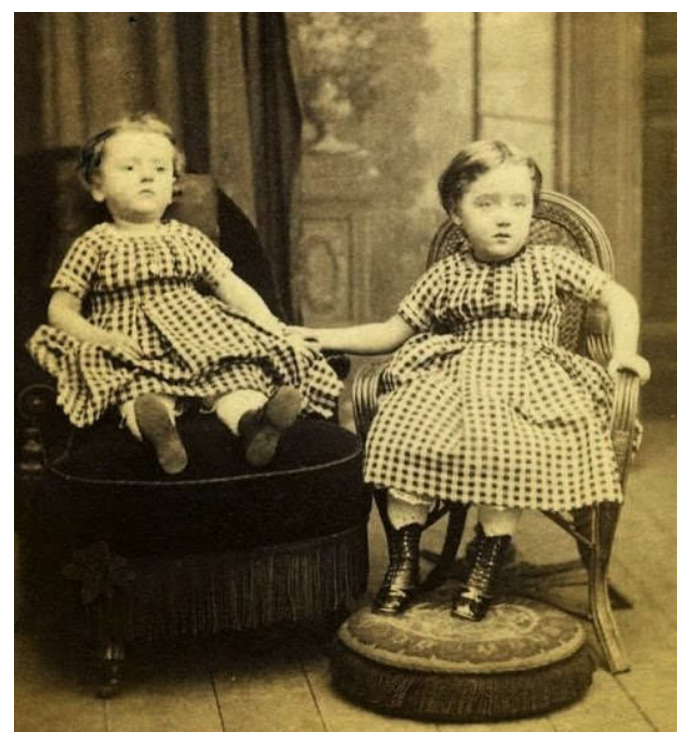

Fonte: Google imagens

Na fotografia, contemplamos duas crianças. A primeira delas, da esquerda para a direita, está morta. Se observarmos com atenção, perceberemos seu corpo levemente decaído, uma inércia a mais do que pediria uma situação de pose para ser fotografada. Seu olhar não tem horizonte. É fixo, vazio, fundo. Falta-lhe movimento dentro do instante, falta-lhe alçar-se ao quase que a fotografia representa, este objeto artístico que com um clique rápido aprisiona espectros de nós mesmos num espaçotempo irrecuperável e marcado pela morte de um pouco do que vive em cada um. Imagens que nos olham e imagens que vemos.

\footnotetext{
${ }^{9}$ Aqui, agradeço à Profa. Regina Dalcastagnè, da Universidade de Brasília, que em conferência proferida na ABRALIC 2017, intitulada "Literatura e resistência no Brasil hoje", recorreu ao uso de uma foto post mortem para se referir ao momento político que vivemos e a partir da qual me inspirei para fazer semelhante uso nesse texto.
} 
Mesmo na prisão da foto é possível depreender algum rastro de movimento, como em Avalovara, de Osman Lins, onde lidamos com uma ebulição de angústias, medos, lutas e dramas lutando por expressão dentro da forma perfeita, equilibrada, da narrativa, traço de destaque na prosa do pernambucano. Nesses tempos sombrios, de esperanças empalidecidas e revoltas rubras, fica o convite ao movimento, alegoria maior da vida. Que ocupemos um lugar diferente da criança morta, um lugar de vida e dança, um lugar de mobilização contínua pelo direito ao livro, à leitura, à literatura e à biblioteca - fragmentos da experiência humana que podem nos animar a resistir e transformar criativa e democraticamente o que precisa ser mudado.

Não podemos esquecer que o golpe de 2016 é um ataque contra direitos trabalhistas, contra nossas reservas e recursos naturais, contra a autonomia nacional. É um conjunto de ações cujo objetivo é destruir direitos e lotear a nação para o capital internacional, a todo custo e com o apoio irrestrito de banqueiros, latifundiários e mercadores da "fé" que espoliam milhões de pessoas. Para isso, eles precisaram interromper os avanços democráticos que experienciamos nos últimos anos, que também são estéticos, artísticos, culturais e pedagógicos.

O historiador Lucien Bianco diz que as armas dos fracos são sempre fracas armas. Mesmo assim, é preciso lutar com o que temos. Nossas armas são as palavras e os afetos e com eles precisamos ocupar territórios, reinventar práticas, desmascarar a história e a memória hegemônicas e criar espaços pulsantes de vida capazes de rivalizar e romper com o medo e a incerteza que nublam o dia a dia de um país doente. Crônica da ignorância, do ódio, da intolerância e da estupidez, o fascismo tropical tem se fortalecido e vomitado seus monstros, a exemplo do presidente eleito e seus comparsas. Resistiremos com unhas, dentes, sangue e palavras. Como a flor drummondiana, que furou o asfalto, o tédio, o nojo e o ódio para anunciar o lugar resistente do sensível entre os brutos, precisamos permanecer e seguir construindo lutas com radicalismo e amor críticos, ratificando a fala sábia de Conceição Evaristo, uma das nossas mais brilhantes escritoras contemporâneas: eles combinaram de nos matar, mas nós combinamos de não morrer.

\section{Referências}


AÇÃO EDUCATIVA ASSESSORIA, PESQUISA E INFORMAÇÃO (Org.). A ideologia do movimento Escola sem Partido: 20 autores desmontam o discurso. São Paulo: Ação Educativa, 2016.

ARROYO, Miguel G.. Currículo, território em disputa. $5^{\mathrm{a}}$ ed. Petrópolis: Vozes, 2012b.

ARROYO, Miguel G.. Outros Sujeitos, Outras Pedagogias. $1^{\mathrm{a}}$ ed. Petrópolis: Vozes, $2012 \mathrm{a}$. ARROYO, Miguel G.. Passageiros da noite - Do trabalho para a EJA: itinerários pelo direito a uma vida justa. $1^{\underline{a}}$ ed. Petrópolis: Vozes, 2017.

ASSOCIAÇÃO BRASILEIRA DE CURRÍCULO (ABdC). Documento produzido pela Associação Brasileira de Currículo (ABdC) encaminhado ao CNE no contexto das Audiências públicas sobre a BNCC /2017. Rio de Janeiro, 2017.

ASSOCIAÇÃO NACIONAL DE PÓS-GRADUAÇÃO E PESQUISA EM EDUCAÇÃO (ANPEd). Ofício no o1/2015/GR a Presidente da Comissão Bicameral da Base Nacional Comum Curricular. Rio de Janeiro, 2015.

ASSOCIAÇÃO NACIONAL DE PÓS-GRADUAÇÃO E PESQUISA EM EDUCAÇÃO (ANPEd). Nota da ANPEd sobre a entrega da terceira versão da Base Nacional Comum Curricular (BNCC) ao Conselho Nacional de Educação. Rio de Janeiro, 2017.

BOURDIEU, Pierre; PASSERON, Jean-Claude. Los estudiantes y la cultura. Editorial Labor, 1967. (Nueva Colección Labor).

BRASIL. Instituto Brasileiro de Geografia e Estatística (IBGE). Pesquisa nacional por amostra de domicílios, 1992/2011 - Taxa de analfabetismo por grupos de idade, 2011.

BRASIL. Lei de Diretrizes e Bases da Educação Nacional. Lei no 9.394, 20 de dezembro de 1996.

BRASIL. Plano Nacional do Livro e da Leitura. Brasília: Ministério da Cultura, 2006.

BRASIL. Portaria Interministerial no 1442, de 10 de Agosto de 2006. In: MARQUES NETO, J. C. (Org.). PNLL: textos e história. São Paulo: Cultura Acadêmica Editora, 2010. BRASÍLIA (Distrito Federal). Edital no 02 de 04 de junho de 2018. Edital de Convocação para o Processo de Inscrição e Avaliação de Obras Literárias para o Programa Nacional do Livro e do Material Didático PNLD 2018 Literário. MEC/FNDE/SEB. Portal do MEC. CANDIDO, Antonio. O direito à literatura. In: Vários escritos. 5‥ ed. São Paulo; Rio de Janeiro: Duas Cidades; Ouro sobre Azul, 2011. 
CANÔNICA, Volnei. DLLLB continua em queda vertiginosa e vira um departamento na nova configuração do MinC. 2016. Disponível em: http://www.publishnews.com.br/materias/2016/o8/18/dlllb-continua-em-quedavertiginosa-e-vira-um-departamento-na-nova-configuracao-do-minc. Acesso: 27.06.2018.

CANÔNICA, Volnei. Para onde vão as políticas do livro e da leitura do MinC? 2016. Disponível em: http://www.publishnews.com.br/materias/2016/o7/26/para-onde-vaoas-politicas-do-livro-e-da-leitura-no-minc. Acesso: 20.06.2018.

CARA, Daniel. O Programa "Escola sem Partido" quer uma escola sem educação. In: AÇÃO EDUCATIVA ASSESORIA, PESQUISA E INFORMAÇÃO (Org.). A ideologia do movimento Escola sem Partido: 20 autores desmontam o discurso. São Paulo: Ação Educativa, 2016.

CAVALCANTE, Talita Lopes. Fotografias Post Mortem: prática comum na Era Vitoriana. 2013. Disponível em: http://www.museudeimagens.com.br/fotografias-post-mortem/. Acesso: 27.07.18.

DALCASTAGNÈ, Regina. Literatura e resistência no Brasil hoje. 2017. Disponível em: https://suplementopernambuco.com.br/artigos/1936-literatura-e-resist\%C3\%AAnciano-brasil-hoje.html. Acesso: 14.05.18.

GARCIA, Fernanda. PNLE, afinal de contas o que virou lei? 2018. http://www.publishnews.com.br/materias/2018/o7/16/pnle-afinal-de-contas-o-quevirou-lei. Disponível em: http://www.publishnews.com.br/materias/2018/o7/16/pnleafinal-de-contas-o-que-virou-lei. Acesso: 27.07.18.

LAHIRE, Bernard. A cultura dos indivíduos. Porto Alegre: Artmed, 2006.

LAHIRE, Bernard. Retratos sociológicos: disposições e variações individuais. Porto Alegre: Artmed, 2004.

LINS, Osman. Avalovara. Apresentação de Antonio Candido. $2^{\underline{\underline{a}}}$ ed. São Paulo: Melhoramentos, 1974 .

NOGUEIRA, Maria Alice \& CATANI, Afrânio. (Orgs.). Escritos de Educação (Pierre Bourdieu). Petrópolis, RJ: Vozes, 2015.

PARAÍSO, Marlucy Alves. Diferença no currículo. Cadernos de Pesquisa, v. 40, n. 140, p. 587-604, maio/ago., 2010.

PARAÍSO, Marlucy Alves. Pesquisas pós-críticas em educação no Brasil: esboço de um 
mapa. Cadernos de Pesquisa, v. 34, n. 122, p. 283-303, maio/ago., 2004.

PARAÍSO, Marlucy Alves. Um currículo entre formas e forças. Educação, v. 38, n. 1, p. 49-58, jan.-abr., 2015 .

PASSERON, Jean-Claude. Biographies, flux, itinéraires, trajectoires. Revue française de sociologie, v. XXXI, n. 1, p. 3-22, 1989.

QUEIROZ, Bartolomeu Campos de. Manifesto por um Brasil Literário. Rio de Janeiro: Movimento Brasil Literário (MBL), 2009.

TIBURI, Marcia. Como conversar com um fascista: reflexões sobre o cotidiano autoritário brasileiro. Rio de Janeiro: Record, 2016.

Recebido em 16/o9/2018.

Aprovado em 10/12/2018. 